\title{
A percepção de crianças escolares acerca da hospitalização: estudo com dados qualitativos
}

\author{
A perception of school children about hospitalization: study with qualitative data \\ La percepción de niños escolares acerca de la hospitalización: estudio com datos \\ cualitativos
}

Ozeias Pereira de Oliveira ${ }^{1}$, Hercules Pereira Coelho ${ }^{2 *}$, Luzianne Clemente de Meneses ${ }^{3}$, Carlos Vinicius Moreira Lima ${ }^{4,5}$, Janayle Kéllen Duarte de Sales ${ }^{2}$, Gilberto dos Santos Dias de Souza ${ }^{2}$, Joseph Dimas de Oliveira ${ }^{6}$, Ana Paula Ribeiro de Castro $^{2}$, Ana Maria Machado Borges², Ana Raquel Bezerra Saraiva Tavares?.

\section{RESUMO}

Objetivo: Compreender a percepção da criança escolar frente à hospitalização. Métodos: Trata-se de um estudo qualitativo, realizado em um hospital pediátrico público de referência para a $21^{\text {a }}$ Macrorregião de Saúde Juazeiro do Norte, Ceará. A pesquisa foi realizada entre os meses de fevereiro a novembro de 2017. A população do estudo foram 10 crianças escolares. Os dados foram coletados por meio de uma entrevista semiestruturada e analisados por através da análise de conteúdo. Resultados: A partir da análise dos dados emergiram duas categorias temáticas: percepção da criança escolar acerca da internação, e a visão da criança diante da hospitalização. A partir destas pôde-se compreender a visão e/ou opinião da criança sobre a hospitalização e os motivos relacionados à mesma, os sentimentos e experiências vivenciados pelas crianças durante este episódio, a percepção destas quanto ao ambiente hospitalar, atividades e procedimentos desenvolvidos durante este período, e a atenção advinda dos profissionais da saúde. Considerações finais: Conclui-se, a partir do estudo, que as crianças percebem e entendem os motivos da internação hospitalar, e que apesar de relacionarem a hospitalização somente com a realização de procedimentos invasivos e dolorosos, elas compreendem a necessidade destes para a recuperação de sua saúde.

Palavras-chave: Hospitalização, Enfermagem pediátrica, Cuidado da criança.

\begin{abstract}
Objective: To understand the perception of schoolchildren regarding hospitalization. Method: This is a qualitative study, carried out in a public pediatric hospital of reference for the 21st Health Macro-region Juazeiro do Norte, Ceará. The research was carried out between February and November 2017. The study population was 10 school children. Data were collected through a semi-structured interview and analyzed using content analysis. Results: From the data analysis, two thematic categories emerged: perception of school child about hospitalization, and view of child regarding hospitalization. From these it was possible to understand the view of child and / or opinion about hospitalization and the reasons related to it, the feelings and experiences experienced by children during this episode, their perception of the hospital environment, activities and procedures developed during this period, and the attention from health professionals. Final considerations: It is concluded from the study that children understand the reasons for hospital admission, and that although they relate hospitalization only to invasive and painful procedures, they understand the need for them to recover their health.
\end{abstract}

Keywords: Hospitalization, Pediatric nursing, Child care.

\footnotetext{
${ }^{1}$ Faculdades Integradas de Patos (FIP), Crato - CE.

${ }^{2}$ Centro Universitário Doutor Leão Sampaio (UNILEÃO), Juazeiro do Norte - CE. *E-mail: herculesleon_01@yahoo.com

${ }^{3}$ Instituto de Medicina Integral Prof. Fernando Figueira (IMIP), Recife - PE.

${ }^{4}$ Escola de Saúde Pública do Ceará (ESP-CE), Fortaleza - CE

5 Instituto Doutor José Frota (IJF), Fortaleza - CE.

${ }^{6}$ Universidade Regional do Cariri (URCA), Crato - CE.

${ }^{7}$ Universidade Estadual do Ceará (UECE), Fortaleza - CE.
} 


\section{RESUMEN}

Objetivo: Comprender la percepción de los escolares sobre la hospitalización. Método: Este es un estudio cualitativo, realizado en un hospital pediátrico público de referencia para la $21^{\underline{a}}$ Región de Macro-Salud Juazeiro do Norte, Ceará. La investigación se realizó entre los meses de febrero y noviembre de 2017. La población de estudio fue de 10 escolares. Los datos fueron recolectados a través de una entrevista semiestructurada y analizados a través del análisis de contenido. Resultados: Del análisis de datos surgieron dos categorías temáticas: percepción de hospitalización de los escolares y la visión del niño sobre la hospitalización. A partir de estos, fue posible comprender la opinión y/o opinión del niño sobre la hospitalización y las razones relacionadas, los sentimientos y experiencias experimentados por los niños durante este episodio, su percepción del ambiente hospitalario, las actividades y los procedimientos desarrollados durante este período y la atención de los profesionales de la salud. Consideraciones finales: Se concluye del estudio que los niños comprenden y entienden las razones de la admisión en el hospital, y que aunque relacionan la hospitalización sólo con procedimientos invasivos y dolorosos, comprenden la necesidad de que recuperen su salud.

Palabras clave: Hospitalización, Enfermería pediátrica, Cuidado de niños.

\section{INTRODUÇÃO}

A infância é uma etapa fundamental para o desenvolvimento pleno do ser humano, um período de intensa construção nos planos cognitivo, motor, de aprendizagem na escola e junto à família, através da qual a mesma constrói uma relação com a sociedade, e molda seu comportamento e personalidade por meio de uma visão distinta do mundo. O alicerce para o desenvolvimento dessas relações sociais e interpessoais advém de descobertas e aquisições, que são construídas no decorrer da sua história, por meio da interação com o meio ambiente e com os indivíduos (HOCKENBERRY MJ e WILSON D, 2014; OLIVEIRA LDB, et al., 2009).

Por ser a infância um estágio marcado por intensas brincadeiras e atividades físicas, torna-se necessário que a criança possua saúde. Todavia, no decorrer do seu desenvolvimento, a mesma pode apresentar quadros de enfermidades, como as infecções causadas por vírus e bactérias típicas da infância, o que pode direcioná-la à necessidade de internação hospitalar (OLIVEIRA LDB, et al., 2009).

De acordo com o DATASUS as principais enfermidades que acometem as crianças em idade pré-escolar e escolar, dos três aos dez anos de idade, são as: infecções em decorrência de vírus, bactérias e parasitas, bem como as patologias que acometem as glândulas endócrinas, o metabolismo, o sistema nervoso, cardiocirculatório, infecções respiratórias, e as afecções perinatais (BRASIL, 2016). Essas patologias identificadas, em maior grau, podem direcionar a criança a necessidade de hospitalização (MALTA DC e DUARTE EC, 2007).

Durante a internação hospitalar as crianças são submetidas a vários procedimentos invasivos, e por vezes dolorosos, com o intuito de favorecer o reestabelecimento de sua saúde. No entanto, este processo pode contribuir ainda de maneira negativa para a mesma, haja vista o distanciamento desta com seu ambiente social comum e a necessidade de adaptação ao meio (FERREIRA NAS, et al., 2014).

Para a criança o ambiente hospitalar apresenta-se como um fator estressor, o qual pode interferir no seu estado psicológico. Através de suas expressões, sentimentos, comportamentos e reações emocionais, durante a hospitalização, a criança pode apresentar sofrimento psíquico, frequentemente diferente do habitual. Esse sofrimento pode ser decorrente do medo da dor, das agulhas, dos exames e, muitas vezes, devido à separação do seu grupo familiar (SANCHEZ MLM e EBELING VLN, 2011).

A enfermagem tem em sua essência $o$ ato de cuidar, e diante desse pressuposto, apresenta um papel fundamental, que consiste em assistir a criança durante a internação, e proporcionar meios para uma assistência equânime. Sendo que, para isso é necessária a construção de uma boa relação entre os profissionais de saúde, as crianças e os seus respectivos acompanhantes. Dessa forma, em meio a uma assistência holística, torna-se possível minimizar os danos e traumas decorrentes do processo de 
hospitalização, bem como favorecer um ambiente saudável, no qual a criança possa interagir com o meio, o que possibilita uma melhor adesão ao tratamento (GOMES GC, et al., 2015).

A pesquisa apresenta significativa contribuição social, frente a possível minimização de traumas ou inseguranças decorrentes do processo de internação hospitalar, a partir da compreensão dos profissionais de saúde quanto à percepção da criança diante do quadro de enfermidade. Assim, definiu-se como hipótese que a criança enferma consegue compreender a sua internação e reage de acordo com a abordagem de tratamento realizado pela equipe. Têm-se como objetivo do estudo, compreender a percepção da criança escolar frente à hospitalização.

\section{MÉTODOS}

Trata-se de um estudo qualitativo, realizado em um hospital pediátrico público de referência para a $21^{\text {a }}$ Macrorregião de Saúde Juazeiro do Norte, Ceará. O estudo foi construído no período de fevereiro a novembro de 2017, sendo a coleta dos dados concretizada no mês de outubro do referido ano, nos horários matutino, vespertino e noturno, durante o período de 10 dias, com o intuito de angariar o máximo possível de participantes.

A pesquisa foi realizada junto às crianças escolares internadas no referido hospital, a partir da observância aos critérios de inclusão: crianças escolares que estivessem internadas no setor de pediatria da supracitada instituição hospitalar há pelo menos dois dias; com idade entre seis a dez anos; e dos critérios de exclusão: crianças que aguardavam somente para consulta médica, sem quadro de internação; crianças escolares com transtornos psiquiátricos; crianças com desorientação alopsíquica e autopsíquica; portadores de Transtorno do Espectro Autista; e crianças portadoras de grandes queimaduras.

Após leitura do Termo de Consentimento Livre e Esclarecido (TCLE) e conseguinte assinatura dos Termos de Consentimento Pós-Esclarecido (TCPE) pelos pais e/ou responsáveis da criança, e do Termo de Assentimento pela criança, foi realizada a escolha de codificações, a saber: entrevistado 1, entrevistado $2 \ldots$ de modo a manter o anonimato das crianças, sendo que, posteriormente, deu-se início a aplicação do instrumento de coleta.

Para obtenção dos dados foi utilizada uma entrevista semiestruturada, aplicada às crianças internadas na unidade hospitalar, a partir da qual seus monólogos foram gravados e, posteriormente transcritos na íntegra pelos pesquisadores. A análise dos dados foi realizada por meio da Análise de Conteúdo proposta por Minayo MCS (2014), a partir da realização de leituras do conteúdo e uma codificação flutuante.

Ressalta-se que a pesquisa obedeceu aos aspectos éticos e legais estabelecidos pela Resolução no 466/12, do Conselho Nacional de Saúde, que rege através de normas e diretrizes a realização de pesquisas com seres humanos, sendo a mesma aprovada pelo Comitê de Ética em Pesquisa do Centro Universitário Doutor Leão Sampaio (UNILEÃO), com o parecer consubstanciado de oo 2.307 .090 e CAAE: 70894617.0.0000.5048.

\section{RESULTADOS}

Após a leitura dos monólogos, emergiram duas categorias temáticas, sendo estas: percepção da criança escolar acerca da internação, e a visão da criança diante da hospitalização. Realizou-se, primariamente, a caracterização dos sujeitos da pesquisa, a partir das seguintes variáveis: idade, sexo, nível de escolaridade e diagnóstico médico. $O$ estudo foi composto por 10 crianças, com idade entre 06 a 10 anos, sendo 07 do sexo masculino e 03 do sexo feminino. Quanto ao nível de escolaridade isso cursavam entre o $1^{\circ}$ e $5^{\circ}$ ano do ensino fundamental I, e estavam internadas em detrimento de diagnósticos médicos frequentes para idade, a saber: asma, celulite, enteroinfecção, pneumonia, gastroenterite, leishmaniose e hérnia inguinal.

\section{Categoria Temática I: Percepção da criança escolar acerca da internação}

Esta categoria denomina-se "Percepção da criança escolar acerca da internação" por tratar da visão e/ou opinião da criança sobre a hospitalização e os motivos relacionados à mesma, bem como os sentimentos e experiências vivenciados pelas mesmas durante este episódio. 
Diante da percepção dos escolares quanto ao motivo de sua internação, foram evidenciadas visões diferenciadas, sendo possível, a partir destas, conhecer suas experiências com a hospitalização e o adoecimento, verificando o sofrimento gerado durante esse processo, como ilustra as falas a seguir:

"Eu levei um acidente de moto" (Entrevistado 1).

"Estou com pneumonia e muito doente" (Entrevistado 2).

"Tô doente de calazar" (Entrevistado 3).

"[...] estou com vômito e diarreia" (Entrevistado 4).

"[...] estou doente. Estou com asma" (Entrevistado 5).

"É porque tive febre alta, fiquei sem comer" (Entrevistado 6).

"Não sei por que mainha veio me levar para o hospital" (Entrevistado 7).

"Porque eu me machuquei e senti muita dor, aí minha mãe me trouxe para o hospital" (Entrevistado 8).

Ao indagá-las quanto ao seu sentimento diante do quadro de afecção, e conseguinte internação hospitalar, observou-se:

"Eu não sinto nada" (Entrevistado 1).

"Me sinto bem, pois estou sendo cuidado" (Entrevistado 7).

"Me sinto bem" (Entrevistado 6).

"Tô bem! Tomei soro" (Entrevistado 8).

"Estou com dor aqui [região abdômen]" (Entrevistado 4).

"Ruim, pois estou longe de casa" (Entrevistado 9).

"Ruim, porque eu queria assistir desenho" (Entrevistado 2).

Pôde-se visualizar a importância do cuidado realizado pelos profissionais de saúde, durante o período de internação das crianças, através das falas:

"Eles cuidam bem de mim, na hora que vêm aqui no quarto" (Entrevistado 1).

"Bem, me tratam super bem" (Entrevistado 2).

"Cuidam bem de mim, são muito legais" (Entrevistado 3).

"Muito bom, vem colocar remédio aqui [Acesso Venoso Periférico]"

(Entrevistado 7).

"Bem, são os melhores doutores" (Entrevistado 9).

"Me dão remédio, cuidam bem de mim" (Entrevistado 5).

"Eles me tratam bem" (Entrevistado 6).

"Cuidam bem de mim" (Entrevistado 4; Entrevistado 8).

É notório que para assistir a criança de maneira equânime é necessário ir além do seu quadro clínico, permitindo-Ihes um ambiente agradável e qualitativo que favoreça sua recuperação física, biológica e psicossocial, sendo para isto, possível a utilização de ferramentas lúdicas pelos profissionais da saúde, com o intuito de proporcionar à criança novas experiências e, deste modo, ampliar seus relacionamentos interpessoais.

Neste contexto, ressalta-se que na instituição de saúde, lócus da coleta dos dados, são realizadas semanalmente intervenções lúdicas com as crianças e seus acompanhantes, por grupos voluntários, dos 
cursos de graduação em Enfermagem e Medicina. Ações estas que, quando questionado as crianças como elas se sentiam foi perceptível seus efeitos benéficos, pois favorece a melhoria do quadro clínico das mesmas, haja vista alegrar o ambiente e promover a interação social entre as crianças, acompanhantes e profissionais da saúde, conforme evidenciado nas falas a seguir:

"Alegria, um pouco de medo" (Entrevistado 3).

"Me sinto muito bem quando eles [grupos lúdicos] vêm aqui" (Entrevistado 4; Entrevistado 7).

"Alegria, feliz, muito agradecida" (Entrevistado 9).

"Fico feliz, alegre quando eles [grupos lúdicos] vêm aqui" (Entrevistado 2).

$\mathrm{Na}$ percepção das crianças, os cuidados hospitalares relacionam-se à realização de procedimentos técnicos invasivos e dolorosos, o que as deixam tristes e ansiosas. Porém, também entendem que estes procedimentos são necessários para a recuperação de sua saúde e, consequentemente, para obtenção da alta hospitalar. Esse fato é evidenciado nas falas dos participantes:

“Triste quando é para injeção, bom quando vou brincar" (Entrevistado 8).

"Fico com raiva quando eles vêm aqui" (Entrevistado 6).

"Me sinto triste, pois eu não gosto da agulhada" (Entrevistado 10).

"Eu fico com medo de doer" (Entrevistado 1).

"Um pouquinho triste, pois estou longe de casa" (Entrevistado 5).

Podemos visualizar a importância do cuidado realizado pelos profissionais de saúde quando indagamos às crianças escolares: Como vocês gostariam de serem cuidados pelos profissionais?

"Que eles me dessem alta amanhã daqui, e mais atenção" (Entrevistado 2).

"Que me tratassem bem, com mais atenção" (Entrevistado 9).

"Bem, durante a medicação queria que eles me furassem direito" (Entrevistado 5).

"Não me dando injeção, me dão muito forte, isso dói" (Entrevistado 6).

"Que eles não me furassem mais, pois dói muito, tenho medo" (Entrevistado 10).

"Que não dessem injeção em mim" (Entrevistado 8).

A partir dos relatos supracitados, pôde-se perceber que no ambiente hospitalar a criança vivencia uma nova rotina, atrelada aos aspectos relacionados à sua doença e aos cuidados realizados pela equipe.

\section{Categoria Temática II: Visão da criança diante da hospitalização}

Esta categoria denomina-se "Visão da criança diante da hospitalização" por abordar a percepção destas quanto ao ambiente hospitalar, atividades e procedimentos desenvolvidos durante este período, e a atenção advinda dos profissionais da saúde.

Quando questionados quanto à visão que as crianças detêm acerca do hospital, foram mencionadas diferentes percepções, a princípio seis mencionaram que gostavam do hospital, mostrando a relevância deste para a sua saúde:

"É um lugar bom" (Entrevistado 1).

"Acho que o hospital é bom" (Entrevistado 2).

"Eu vejo bem" (Entrevistado 5).

"Vejo como uma coisa muito importante, cuidam bem de mim aqui"

(Entrevistado 7). 
"Eu gosto, pois aqui eu estou sendo cuidada" (Entrevistado 8).

"É um lugar muito bom, pois eles prestam cuidados para nós" (Entrevistado 10).

Em contrapartida, foi possível evidenciar ainda a visão negativa que as mesmas detêm acerca do hospital, sendo perceptível a expressão do sentimento de saudade de seu lar, através das falas a seguir:

"Não gosto muito de hospital" (Entrevistado 9).

"Mais ou menos, pois gostaria de estar em casa" (Entrevistado 4).

"Eu acho que bom, é um pouquinho bom e muito ruim" (Entrevistado 6).

"Tem muitas pessoas doentes" (Entrevistado 3).

Ao perguntar o que mais gostam no hospital, as crianças demonstraram sua visão acerca da hospitalização, sendo evidenciadas nas falas a seguir:

"Dos palhaços [grupos lúdicos] que fazem a visita, do parquinho, e dos coleguinhas" (Entrevistado 1).

"Eu gosto da sopa de arroz, e do parquinho que tem lá fora" (Entrevistado 6).

"Porque eu posso ficar bom, e do parquinho" (Entrevistado 2).

"Os palhaços [grupos lúdicos] que vêm fazer a visita, e do parquinho de diversão" (Entrevistado 3).

"Gosto do parquinho, lá eu brinco muito" (Entrevistado 5; Entrevistado 7;

Entrevistado 10).

"Os brinquedos, e tem o parquinho" (Entrevistado 8).

A partir dos seus monólogos constatou-se ainda o que as crianças não gostam diante da internação, conforme expresso a seguir:

"Só não gosto das injeções" (Entrevistado 1).

"A injeção" (Entrevistado 8).

"Não gosto das furadas" (Entrevistado 9).

"Não gosto quando me furam" (Entrevistado 2).

"Eu não gosto é da medicação, porque tem que me furar para colocar a medicação" (Entrevistado 5).

"Quando vem aqui no quarto para realizar a medicação" (Entrevistado 10).

"Da sopa de arroz, não gosto também das furadas" (Entrevistado 4).

Diante das falas percebe-se que a ocorrência das "furadas" possibilita o surgimento da ansiedade, o que pode comprometer o tratamento. No entanto, a dieta ofertada também possibilita rejeição pelo período de internação, pois pode não ser o alimento de sua rotina familiar.

Quando questionados acerca do que menos gostam, as crianças citaram os procedimentos padrões, os profissionais e o ambiente hospitalar como um todo, relatos estes expressos a seguir:

"Não sei! Não gosto de ser furado, não gosto das médicas, porque elas são horríveis, elas são desse jeito" (Entrevistado 6).

"Não gosto da comida. Reclamei com mainha dos profissionais" (Entrevistado 3).

Assim, as falas dos entrevistados 6 e 3 permitem avaliar como a criança vê o profissional que está realizando a assistência, essa visão poderá sofrer alteração de acordo com o tipo de tratamento que ela recebe. Da mesma forma, a visão da dieta administrada está diretamente relacionada com os hábitos alimentares da família e das restrições impostas com o tratamento. 
Durante o quadro de internação hospitalar, a criança perpassa por momentos de dor, angústia, tristeza e solidão, sentimentos estes que podem ser atenuados mediante a participação familiar e da efetivação de uma assistência humanizada. Em meio às entrevistas realizadas junto aos infantes, vislumbramos relatos que expressam tal sentimento, dentre estes:

"Fico triste, pois meu pai não vem me visitar" (Entrevistado 7).

\section{DISCUSSÃO}

As crianças visualizam sua internação como um ato importante para a promoção de sua saúde e para os cuidados oferecidos, com o intuito de obterem a alta hospitalar (GABATZ RIB e RITTER NR, 2007; QUINTANA AM, et al., 2016). Durante o internamento hospitalar, algumas crianças possuem sentimentos ambíguos, pois ao mesmo tempo em que percebem os procedimentos como negativos, também compreendem a necessidade destes para a melhora e alívio sintomático do seu quadro clínico (QUINTANA AM, et al., 2016).

A criança, frente à hospitalização, pode apresentar dificuldades de enfrentamento, haja vista vislumbrar o hospital como um lugar que provoca sentimentos de tristeza, em decorrência dos diversos cuidados realizados pela equipe e a própria sintomatologia da doença (FERREIRA NAS, et al., 2014; SANCHEZ MLM e EBELING VLN, 2011).

Muitas instituições de saúde possuem diferenças em sua estrutura física, que podem remeter ao medo e, em contrapartida, se for mais lúdica poderá acolher melhor a criança (HOCKENBERRY MJ e WILSON D, 2014; FERREIRA NAS, et al., 2014). O método do brincar deve ser implantado e incorporado à rotina de cuidados, haja vista a importância que a brincadeira traz para um bom tratamento e intervenção durante a realização dos cuidados (BRITO TRP, et al., 2009; MITRE RMA e GOMES R, 2007). A brincadeira permite ainda que a criança aprenda a enfrentar e vivenciar suas emoções, através da sua interação com os profissionais e outras crianças. Assim, o paciente pediátrico, além de reconhecer suas necessidades, percebe que outras crianças também estão vivenciando um processo semelhante ao seu (FONSECA AS e CALEGARI RC, 2013).

Sabe-se que, a criança associa a agulha e a injeção, a dor e ao sofrimento. Deste modo, a realização de tal procedimento pode ser vislumbrado pela mesma como um episódio traumático, principalmente quando a assistência não é humanizada e equânime (DIAS JJ, et al., 2013; CORSANO P, et al., 2015). Assim, vale ressaltar a importância de uma boa relação entre as crianças hospitalizadas e os profissionais de saúde, visto que a equipe de saúde deve atuar na promoção do bem-estar dos clientes que sofrem em decorrência de sua doença, ação esta que pode ser concretizada, de maneira qualitativa, a partir da compreensão destes profissionais quanto aos sentimentos negativos da criança diante da hospitalização, e da necessidade de cuidados que vão além da barreira física (CORSANO P, et al., 2015).

A doença e o quadro de hospitalização constituem as primeiras situações adversas que representam mudanças no estado de saúde das crianças, e, principalmente, da sua rotina familiar. Pelo seu número limitado de mecanismos de enfrentamento que possibilitam se adaptar a nova condição de saúde-doença, a criança sente e percebe a internação de acordo com sua idade e seu desenvolvimento (HOCKENBERRY MJ e WILSON D, 2014). Assim, diante do quadro de hospitalização, a criança percebe o seu estado de enfermidade, e pode a partir deste, desenvolver concepções errôneas ou distorcidas, desde medo, insegurança, angústia a fragilidades. Essas visões podem sofrer mudanças em decorrência da forma utilizada para realizar os cuidados pela equipe de saúde, ou pela hostilidade do ambiente hospitalar (LAPA DF e SOUZA TV, 2011).

Ao mesmo tempo que a criança percebe a hospitalização como benéfica para a sua recuperação, consegue mostrar seus sentimentos de estresse, e enfrentar as situações decorrentes da internação (SANTOS PM, et al., 2016). Neste contexto, a assistência de enfermagem à criança enferma, durante o processo de hospitalização, comumente não tem distinção, pois não é despendido um atendimento diferenciado e/ou humanizado, mesmo sabendo que pode remeter a conflitos com os familiares, o que dificultará a adesão destes ao tratamento (MOLINA RCM e MARCON SS, 2009). 
O enfrentamento da hospitalização para a criança pode remeter a sentimentos negativos, visto que o hospital é um lugar que provoca tristeza, decorrentes da própria sintomatologia da doença, bem como a exposição a procedimentos invasivos, comumente dolorosos. Neste contexto, uma alternativa que viabiliza o acompanhamento durante a internação pediátrica é o uso de intervenções lúdicas, pois através destas a criança é estimulada a alterar sua visão em relação ao ambiente hospitalar, com o intuito de minimizar e/ou eliminar os desconfortos vivenciados diante da internação e terapêutica medicamentosa (COYNE I, 2006; MITRE RMA e GOMES R, 2007).

Os profissionais de saúde devem repassar todas as informações a respeito de tudo que será realizado com a criança no ambiente hospitalar, de forma que permita a compreensão desta e dos seus pais e/ou responsáveis quanto aos procedimentos, medicamentos e exames necessários ao tratamento. Neste ambiente ambíguo, uma abordagem compreensível e humanizada, sobre a dor e os procedimentos médicos e de enfermagem, resultará na obtenção da confiança e cooperação da criança, o que auxilia na conduta do profissional e na evolução diagnóstica (SILVA TP, et al., 2015).

Quando os profissionais de saúde entram no mundo da criança melhoram a interação e facilitam a comunicação com a mesma. Assim, o uso de ferramentas lúdicas permite que a criança se expresse livremente, uma vez que a incentiva a relatar sua experiência de estar doente, e também ajuda a equipe de saúde durante o processo de intervenção e subsequente avaliação (SPOSITO AM, et al., 2016).

Com a presença do familiar, a criança se sente mais segura. Deste modo, a equipe de enfermagem deve integrar sua assistência e seu olhar para envolver não só a criança, mas também os familiares. Ação esta que pode promover a segurança dos envolvidos e o desenvolvimento de uma visão positiva no processo do cuidar, minimizando o estresse e a ansiedade advinda do quadro de internação (SANTOS SMG, 2012).

\section{CONSIDERAÇÕES FINAIS}

Conclui-se, a partir do estudo, que as crianças percebem e entendem os motivos da internação hospitalar, e que apesar de relacionarem a hospitalização somente com a realização de procedimentos invasivos e dolorosos, as mesmas compreendem a necessidade destes para a recuperação de sua saúde. Através das falas das crianças, evidenciou-se a importância de compreender a sua percepção diante da internação hospitalar, como uma alternativa para desenvolver e implementar intervenções que visem à minimização dos fatores nocivos, advindos da hospitalização, o que pode favorecer a promoção de uma assistência equânime, qualitativa e resolutiva, com foco na promoção, prevenção e manutenção da saúde pediátrica, bem como no favorecimento do vínculo entre a tríade criança, profissional e família.

\section{REFERÊNCIAS}

1. BRASIL. Departamento de Informática do Sistema Único de Saúde (DATASUS). Sistema de Informações Hospitalares do SUS (SIH/SUS). Morbidade Hospitalar do SUS por local de Internação. Dados de janeiro de 2015 até março de 2016. 2016. Acesso em: 17 de maio de 2017.

2. BRITO TRP, et al. Práticas lúdicas no cotidiano de enfermagem pediátrica. Esc Anna Nery Ver Enferm. 2009; 13(4): 802-8.

3. CORSANO P, et al. Speakink about emotional events in hospital. the role of health-care professionals in children emotional experiences. Journal of Child Health Care. 2015; 19(1):8492.

4. COYNE I. Children's experiences of hospitalization. Journal of Child Health Care. 104:32636. 2006.

5. DIAS JJ, et al. A experiência de crianças com câncer no processo de hospitalização e no brincar. Rev. Min. Enferm. 2013; 608-613. 2013.

6. FERREIRA NAS, et al. Representação social do lúdico no hospital: o olhar da criança. Rev. bras. crescimento desenvolv. hum. vol.24 n.2. São Paulo - SP. 2014.

7. FONSECA AS, CALEGARI RC. Assistência humanizada na unidade de pediatria. In: Fonseca, AS. Org. Enfermagem Pediátrica. p. 127-47. São Paulo - SP. Martinari. 2013.

8. GABATZ RIB, RITTER NR. Crianças hospitalizadas com fibrose cística: percepções sobre as múltiplas hospitalizações. Rev. bras. enferm. [online]. 2007; 60(1): 37-41.

9. GOMES GC, et al. The meanings attributed by family members in real time in relation to their interactions with the loss. Rev.esc.enferm. USP. 2015; 49(6): 951957.

10. HOCKENBERRY MJ, WILSON D. Fundamentos de Enfermagem Pediátrica. Tradução Maria Inês Corrêa Nascimento. 9º edição. Rio de janeiro; Elsevier. 2014. 
11. LAPA DF, SOUZA TV. Percepção de acadêmicos sobre hospitalização: contribuições para o cuidado de enfermagem. Rev. esc. enferm. USP [online]. 2011; 45(4):811-7.

12. MALTA DC, DUARTE EC. Causas de mortes evitáveis por ações efetivas dos serviços de saúde: uma revisão da literatura. Ciênc. saúde coletiva [online]. 2007; 12: 765-76.

13. MINAYO MCS. O Desafio do Conhecimento: pesquisa qualitativa em saúde. São Paulo; Hucitec; $2014 ; 14: 407$.

14. MITRE RMA, GOMES R. A perspectiva dos profissionais de saúde sobre a promoção do brincar em hospitais. Ciêncsaúdecoletiva. 2007; 12(5): 1277-84.

15. MOLINA RCM, MARCON SS. Benefícios da permanência de participação da mãe no cuidado ao filho hospitalizado. Rev. esc. enferm. USP. [online]. 2009; 43(4): 856-64.

16. OLIVEIRA LDB, et al. A brinquedoteca hospitalar como fator de promoção no desenvolvimento infantil: relato de experiência. Rev. bras. crescimento desenvolv. hum. 2009; 19(2).

17. QUINTANA AM, et al. A vivência hospitalar no olhar da criança internada. Ciênc Cuid Saude, 2016; 64: 414-23.

18. SANCHEZ MLM, EBELING VLN. Internação infantil e sintomas depressivos: intervenção psicológica. Rev. SBPH. vol. 14, n.1. Rio de Janeiro - RJ. jun. 2011.

19. SANTOS PM, et al. Nursing care through the perception of hospitalized children. Rev. Bras. Enferm. 2016; 69(4): 64653.

20. SANTOS SMG. As Necessidades dos Pais da Criança Hospitalizada. Dissertação (Mestrado em Enfermagem de Saúde Infantil e Pediatria). Escola Superior de Saúde. Instituto Politécnico da Guarda. 2012.

21. SILVA TP, et al. Especificidades contextuais do cuidado de enfermagem à criança em condição crônica hospitalizada. Rev. CiencCuidSaude. 2015; 14(2): 1082-1090.

22. SPOSITO AM, et al. Puppets as a strategy forcommunication with brazilian children with câncer. J Nursing\& Health Sciences [online]. 2016; 18(1): 307. 